\title{
Lichen Planus Pemphigoides: A Case Report
}

\author{
Bhuiyan $\mathrm{I}^{1}$, Hossain $\mathrm{MS}^{2}$, Khan MSA 3 , Alam $\mathrm{M}^{4}$, Haque $\mathrm{MA}^{5}$
}

\begin{abstract}
Lichen planus pemphigoides describe a rare subset of patients who usually have typical lichen planus then develop blistering on their lichen planus lesions and in normal skin. Less commonly the blistering antedates the lichen planus. They clinically appear to be a combination of lichen planus and bullous pemphigoid. Oral disease may occur and resemble either lichen planus or bullous pemphigoid. Lichen planus pemphigoides has been triggered by medication \& PUVA. Pruritus may be severe and lesions may evolve to resemble pemphigoid nodularis. Histopathologically lichen planus lesions show lichen planus and bullous lesion shows the features of bullous pemphigoid. DIF is positive in a linear pattern with IgG and C3 along the basement membrane zone, at the roof of saline split skin. The antigen targeted by the autoantibody in Lichen planus pemphigoides is located in the same region as the bullous pemphigoid antigen (at the basal hemidesmosomes). Lichen planus pemphigoides tends to follow a benign and chronic course, even when compared to bullous pemphigoid. We diagnosed a case of Lichen planus pemphigoides on the basis of history, clinical examination, histopathology \& DIF. The patient was treated with systemic \& topical steroid, Dapsone. After 2 month of treatment steroid was withdrawn, but Dapsone continue with no relapse.To our knowledge this is the first diagnosed and treated case in this hospital.
\end{abstract}

Key Words: Lichen planus pemphigoides, bullous lichen planus, Dapsone

\section{Introduction}

Lichen planus pemphigoides (LPP) is a rare condition characterized by the coexistence of bullae and lichen planus, in which the bullae may occur on both clinically normal skin and that involved by lichen planus, subepidermal bullae in histopathology and linear deposists of IgG and $\mathrm{C} 3$ along Basement membrane zone on DIF ${ }^{1}$. Although Lichen planus pemphigoides (LPP) and bullous pemphigoid manifest in different ways clinically, the same antigen may be involved in the immunopathogenesis of these two diseases.

\section{Case Report}

In 10th April 2012, a 40 years old lady presented to the Department of Dermatology and Venereology, Shaheed Suhrawardi Medical College \& Hospital , Dhaka, Bangladesh with 3 months history of pruritic papulovesico bullous skin lesion on both lower extremities with history of diabetis mellitus. She had been treated with various drugs, like antibiotics, antihistamine, analgesic and topical steroid cream with no improvement. On examination we found bilateral nearly symmetrical multiple ,discrete, violaceous ,prutitic ,papules,plaques and

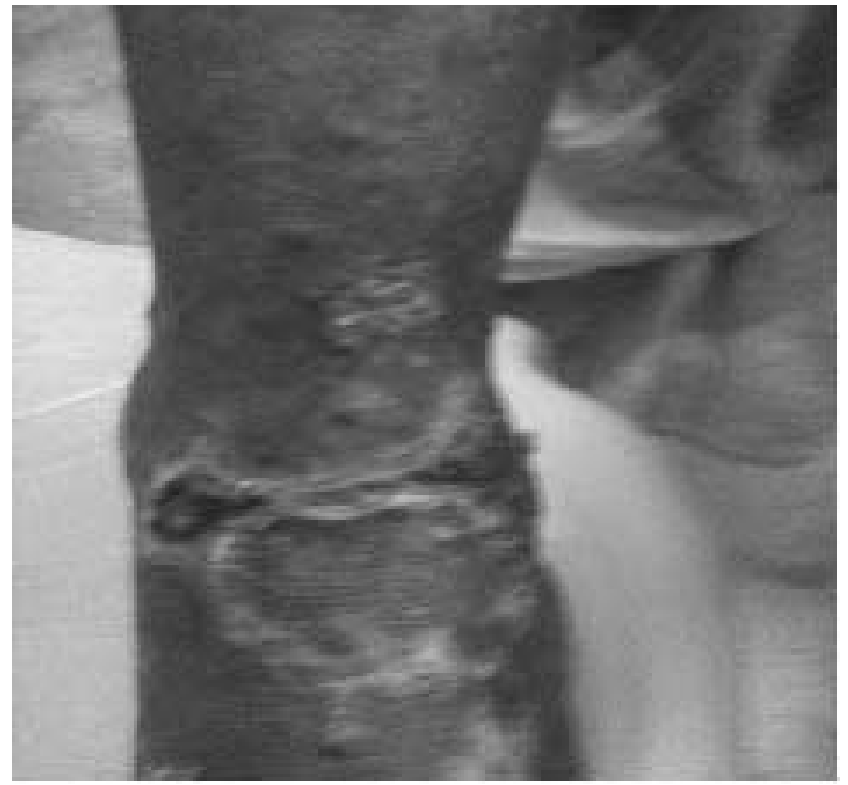

Figure 1a: Violaceous plaques \& eroded areas before treatment.

1. Dr. Ishrat Bhuiyan, Assistant Professor, Department of Dermatology \& Venereology, Shaheed Suhrawardy Medical College, Dhaka

2. Dr. Md. Shahadat Hossain, Assistant Professor, Department of Dermatology \& Venereology, Shaheed Suhrawardy Medical College, Dhaka

3. Dr. Md. Shafique Ahammed Khan, Medical officer, Department of Dermatology \& Venereology, Shaheed Suhrawardy Medical College, Dhaka

4. Col (Dr.) Mahbubul Alam, Classified Specialist \& Professor of Pathology, Armed Forces Medical College (AFMC), Dhaka Cantonment, Dhaka

5. Dr. Md. Azizul Haque, Junior Consultant, Department of Dermatology \& Venereology, Shaheed Suhrawardy Medical College and Hospital, Dhaka

\section{Correspondence}

Dr. Ishrat Bhuiyan, MBBS; DDV, FCPS, Assistant Professor, Department of Dermatology \& Venereology, Shaheed Suhrawardy Medical College and Hospital, Dhaka. Email: ishratskin@yahoo.com; Mobile: +8801711822551 
tense bullae of various size and shape located over the both lower extremites.Bullae appear on the papules,plaques and uninvolved skin.Some of the bullae ruptured and produce oozing, crusting.

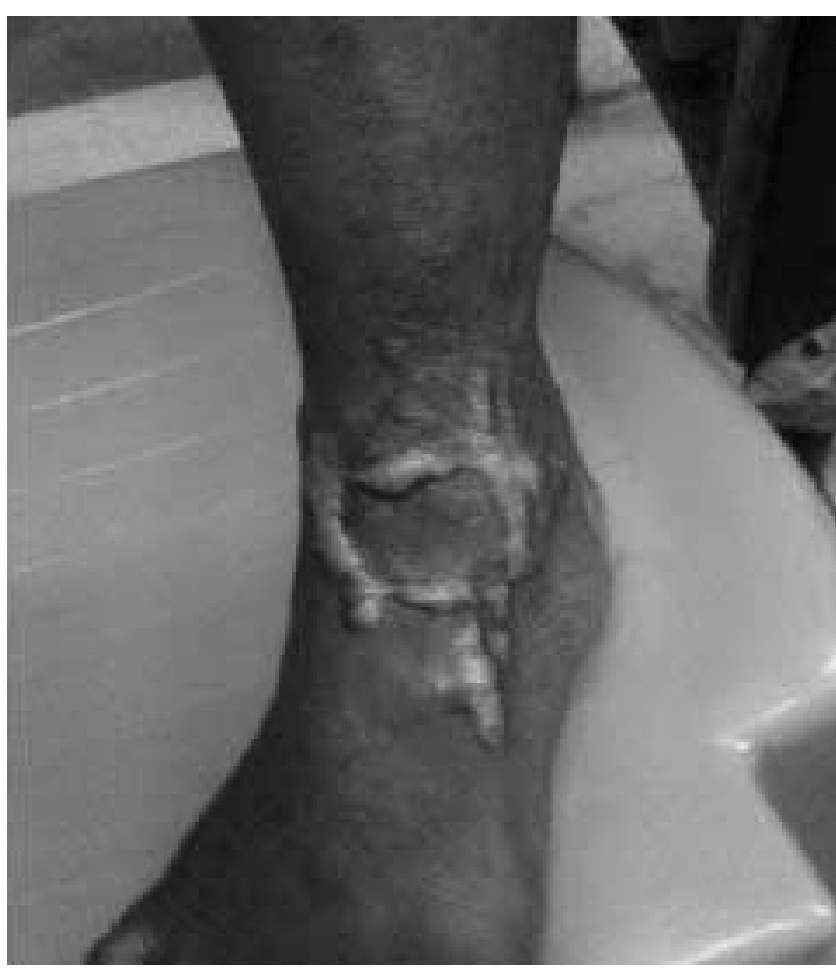

Figure $1 \mathrm{~b}$ : Development of multiple keloids after treatment

A Skin biopsy was taken from a bullae on the plaques showed hyperkeratosis, focal hypergranulosis, irregular acanthosis and sub epidermal bullae containing fibrin and inflammatory cells including neutrrphils and eosinophils . Direct immunofluorescence of perilesional skin found

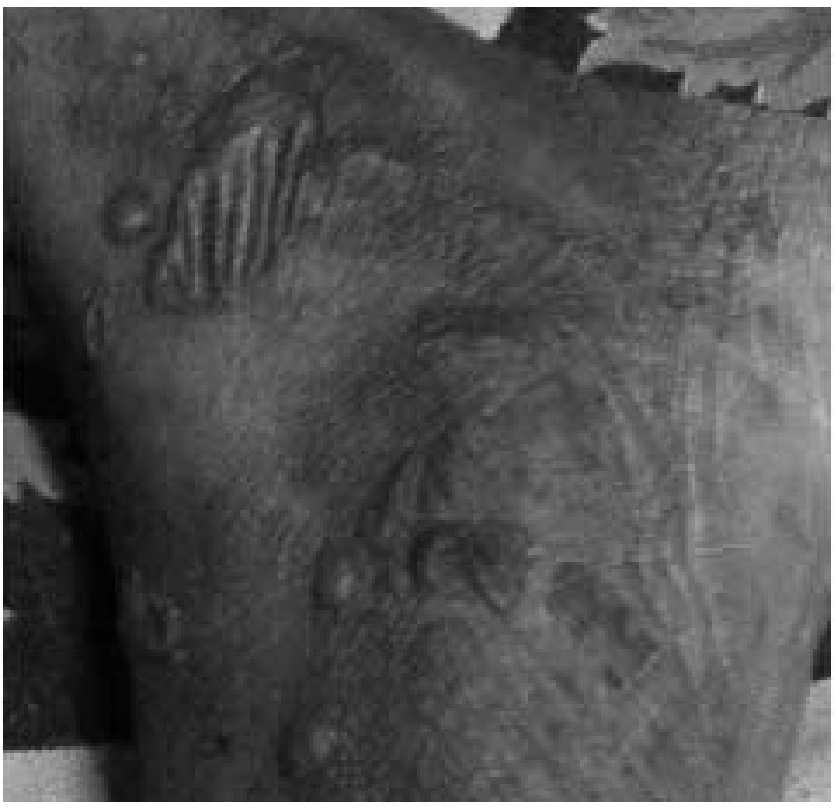

Figure 1c: Multiple tense bullae appearing on normal skin linear deposition of IgG autoantibodies and C3 along the basement membrane zone (BMZ). The histopathology and immunofluorescence was consistent with the diagnosis of lichen plnus pemphigoides(LPP). Circulating anti-BMZ antibodies titre detected by indirect immunofluorescence technique in LPP could not be done due to unavailability in our country. Other haematology and biochemical parameter were normal except fasting blood sugar. Based on clinical and laboratory, a diagnosis of Lichen planus pemphigoides (LPP) with diabetis mellitus was made. Systemic treatment with prednisolone $50 \mathrm{mg}$ /day, dapsone $100 \mathrm{mg} /$ day and topical treatment with clobetasol with mupirocin and injection insulin and other supportive treatment resulted in regression of the disease. The dose of steroid was gradually tapered and stopped after 2 months. No clinical relapse was found. The dose of dapsone still continues as $100 \mathrm{mg} /$ day.

\section{Discussion}

Lichen planus pemphigoides (LPP) is characterized by development of tense blister atop lesions of lichen planus or development of vesicles denovo on uninvolved skin ${ }^{1,23}$.

LPP has been reported to be induced by medication such as cinnarizine, Captopril, ramipril, psoralen \& Ultraviolet A therapy ${ }^{3,4,5}$. The aeitology of LPP remains unclear but the current controversy centres on whether LPP is a distinct entity or whether it represents the coexistence of lichen planus and bullous pemphigoid ${ }^{2,4}$. The primary event may be non-specific cell mediated basal layer damage which

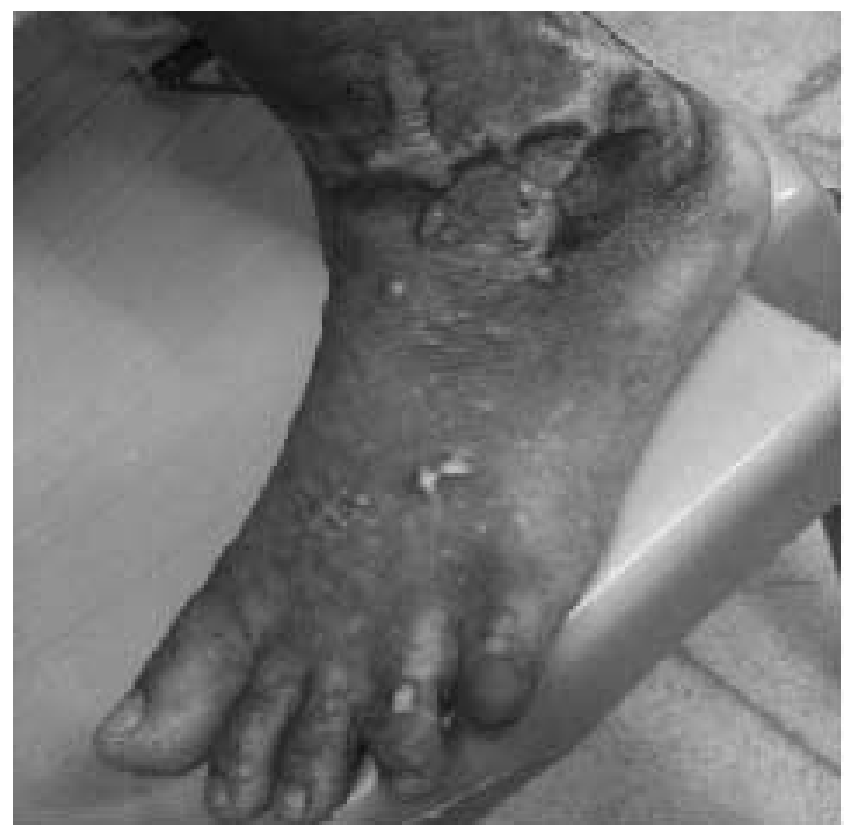

Figure 1d: Development of multiple keloids and post inflammatory hyperpigmentation after treatment

then exposes immunogenic auto antigens or alternatively specific auto antibody binding may lead to dermoepidermal separation ${ }^{2,4}$. In comparison with classical bullous pemphigoid, the course of LPP is less severe ${ }^{5,6,7}$. 
LPP may predominantly affect a younger age group and is responsive to standard treatments used in acquired autoimmune bullous disease ${ }^{8}$. LPP may be treated with topical steroids, systemic steroids, tetracycline \& nicotinamide, isotretinoin, dapsone with immunosuppressive drugs with variable success $5,7,9,10,11$

This patient started with systemic prednisolone $50 \mathrm{mg} /$ day, Dapsone $100 \mathrm{mg} /$ day, Inj. Insulin , topical clobetasol with mupirocin and other supportive treatment resulted regression of the disease. The steroid was tapered gradually and stopped after 2 month but Dapsone continues as starting. No clinical relapse was seen during the follow up period and her diabetic status also controlled. There was brownish pigmented area as well as little keloid formation at some of the lesion areas.

\section{Conclusion}

There is a suggestion that any patient with lichen planus may turn into or will develop Lichen planus pemphigoides (LPP). Bullous lichen planus pemphigoid may develop post inflammatory hyperpigmentation and/or keloid.

\section{References}

1. Mark R. Pittelkow, Mazen S. Daovd. Lichen planus Pemphigoides. In Fitzpatrick's Dermatology in General Medicine. Edn 7th. McGraw Hill, New York, Chicago, Sanfrancisco, Lisbon, London, Madrid, Mexico city, Milan, New Delhi, SanJuan, Seol, Singapore, Sydny, Toranto. 2008;250-251.

2. Breathnach SM. Bullous Lichen planus and Lichen planus pemphigoides. In Rook's Textbook of Dermatology. Edn 8th, vol-2. Edited by Burns T, Breathnach S, Cox N, Griffiths C,. Blackwell publishing. USA, UK .Australia .2010;41.20-41.21

3. Miyagawa S, Ohi H., Muramatsu T., Okuchi T ., Shirai T, Sakamoto K. Lichen planus pemphigoides like lesions induced by Cinnarizine. Br J Dermatol 1985;112, 607-613

4. Ogg GS, Bhogal BS, Hashimoto T, Coleman R, Barker JNWN. Ramipril-associated Lichen planus pemphigoides. $\mathrm{Br} \mathrm{J}$ Dermatol 1997; 136:412-414

5. Demircay Z, Baykal C, Demirkesen C. Lichen planus pemphigoides: report of two ceses. Inter J Dermatol 2001,40, 757-759

6. James WD, Berger TG, Elston DM. Lichen planus and related conditions - Bullous lichen planus. In:Andrews diseases of the skinClinlcal Dermatology. Edn 10th Saunders- Elsevier.Canada. 2006; 220

7. Bouloc A, Vignon-Pennamen M-D, Caux F, et al. Lichen planus pemphigoides is a heterogenous disease; a report of five csses studied by immunoelectron microscopy. Br J Dermatol 1998; 138:972-980.8

8. Sakuma-Oyama Y, Powell AM, Albert S, Oyama N, Bhogal BS, Black MM. Lichen planus pemphigoides evolving into pemphigoid nodularis. Clin Exp Dermatol 2003;28(6):613-616

9. Prost $\mathrm{C}$, Tesserand F, Laroche L, et al. Lichen planus pemphigoides: Immunoelectron microscope study. Br J Dermatol 1985:113:31-36

10. Tamada Y, Yokochi K, Nitta Y, et al. Lichen planus pemphigoides: identification of $180 \mathrm{KD}$ hemidesmosomes antigens. J Am Acad Dermatol 1995:32: 883-887

11. Davis AL, Bhogal BS, Whitehead $\mathrm{P}$, et al. Lichen planus pemphigoides: its relationship to bullous Pemphigoid. Br J Dermatol $1991 ; 125: 263-271$ 